\title{
A New Skin Graft Donor Site Using the Abdominal Dog-Ear Deformity in Mastectomy Flap Necrosis
}

\section{Jong Hyun Choi, Deuk Young Oh}

Department of Plastic and Reconstructive Surgery, Seoul St. Mary's Hospital, College of Medicine, The Catholic University of Korea, Seoul, Korea
No potential conflict of interest relevant to this article was reported.
Background Mastectomy flap necrosis is a common complication after mastectomy and immediate reconstruction with a deep inferior epigastric perforator (DIEP) flap. After abdominal free flap breast reconstruction, the most common secondary procedure is dog-ear correction of both flanks. We introduce a treatment for skin necrosis with a full-thickness skin graft (FTSG) using the abdominal dog-ear deformity.

Methods In patients with skin necrosis of a mastectomy flap, we debrided all necrotic tissue when the demarcation was complete. We then performed an FTSG using the skin from the dog-ear correction of both flank areas. We fixed the graft with a tie-over dressing, and it was then removed on postoperative day 5.

Results Skin necrosis of the mastectomy flap and dog-ear deformity were treated without any complications. The color and texture of the breasts were satisfactory. Conclusions If a patient experiences post-mastectomy skin flap necrosis and has a dogear deformity on both sides of the flank after a DIEP flap, a dog-ear skin flap can be a good alternative donor site for reconstruction.

Keywords Mammaplasty, Mastectomy, Necrosis, Tissue donors, Transplantation autologous

\section{INTRODUCTION}

Recently, our understanding of the vascularity of mastectomy flaps has improved [1]. Nevertheless, mastectomy flap necrosis is a common complication after mastectomy and immediate reconstruction with a deep inferior epigastric perforator (DIEP) flap [2]. If necrosis of a mastectomy flap occurs, additional surgery is required. If the necrotic area is small, it can be treated with an advancement flap or conservative treatment, but if the necrotic area is large, a skin graft may be necessary because of the distortion of the breast. In such cases, we should consider the possibility of additional donor site morbidity.

Received: Aug 16, 2018 Revised: Sep 7, 2018 Accepted: Sep 13, 2018 Correspondence: Deuk Young Oh Department of Plastic and Reconstructive Surgery, Seoul St. Mary's Hospital, College of Medicine, The Catholic University of Korea, 222 Banpo-daero, Seoch-gu, Seoul 06591, Korea. E-mail: ohdeuk1234@hanmail.net

Copyright () 2018 The Korean Society for Aesthetic Plastic Surgery.

This is an Open Access article distributed under the terms of the Creative Commons Attribution Non-Commercial License (http://creativecommons.org/licenses/by-nc/4.0/) which permits unrestricted non-commercial use, distribution, and reproduction in any medium, provided the original work is properly cited. www.e-aaps.org
Patients who have undergone abdominal free flap breast reconstruction usually have dog-ear deformities on both sides of the abdominal scar. After the abdominal free flap breast reconstruction, the most common secondary procedure is dog-ear correction of both flanks [3].

We introduce a method for reconstructing post-mastectomy skin necrosis after nipple-sparing mastectomy (NSM) and DIEP flap reconstruction by selecting remaining skin from the dog-ear excision for the second operation as the donor site for a new fullthickness skin graft (FTSG). This method was successfully performed in 2 cases.

\section{CASE REPORTS}

\section{Patient 1}

A 51-year-old woman underwent NSM of the right breast and immediate breast reconstruction using a DIEP flap. A dog-ear deformity was apparent on both sides of the abdominal donor site (Fig. 1).

The DIEP flap was then stable, but the mastectomy flap gradually became demarcated. She developed skin necrosis of the mastectomy flap, resulting in a significant skin defect $(12 \times 9 \mathrm{~cm})(\mathrm{Fig}$. 2). Afterward, we planned a reconstruction for skin necrosis and 


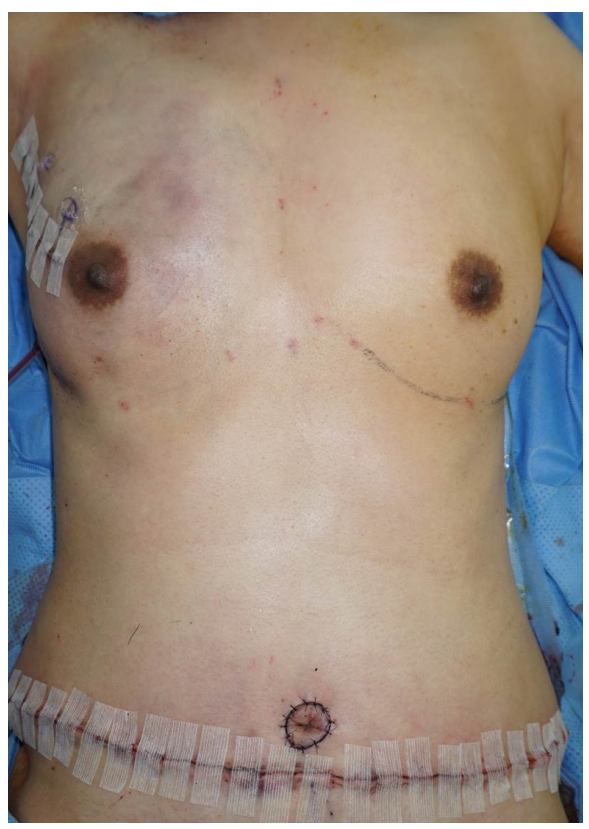

Fig. 1. Immediate postoperative photograph of a patient who underwent nipple sparing mastectomy of the right breast and immediate deep inferior epigastric perforator flap coverage.

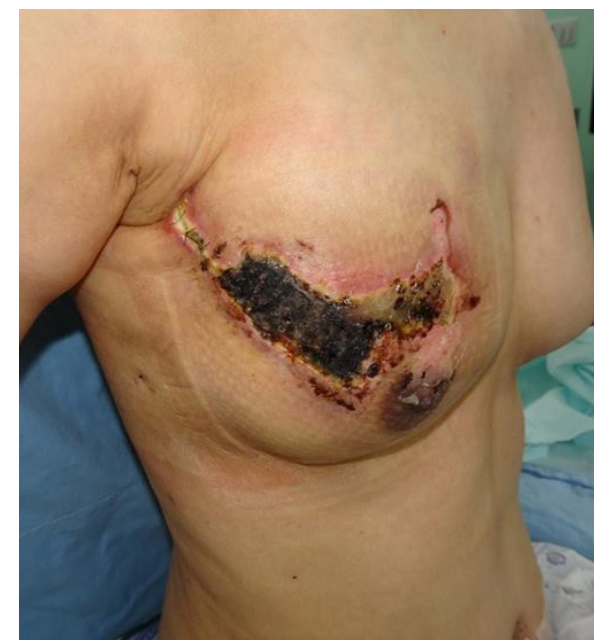

Fig. 2. Preoperative photograph of a patient which was partly necrotized, resulting a significant skin and soft tissue deficit.

dog-ear correction as a secondary procedure.

We created an elliptical design for surgical excision of the dogear deformity. We performed an FTSG using the skin from the dogear correction of both flank areas (left, $5 \times 4 \mathrm{~cm}$; right, $7 \times 5 \mathrm{~cm}$ ) for the defect in the mastectomy area and fixed the graft with a tie-over dressing (Fig. 3). We closed the dog-ear corrected area with \#4-0 polydioxanone, and then applied Steri-strips to maintain the approximation of the skin (Fig. 4). The tie-over dressing was removed on postoperative day 5 and the graft had taken well.

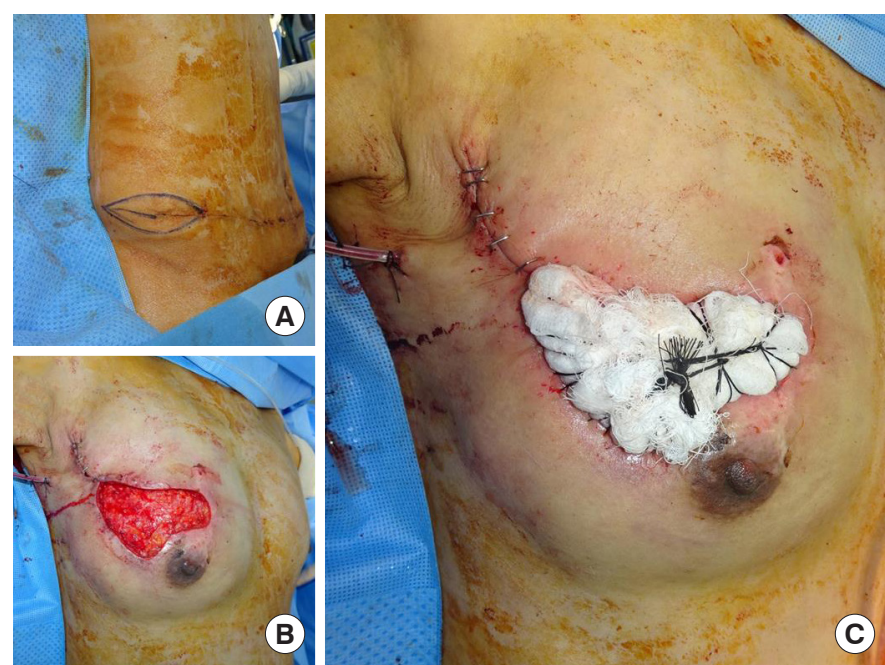

Fig. 3. (A) An elliptical design including the dog-ear deformity of abdominal scar of the previous deep inferior epigastric perforator flap. (B) Postoperative clinical photograph after debridement of entire necrotic. (C) The tie over dressing to fix the skin graft.

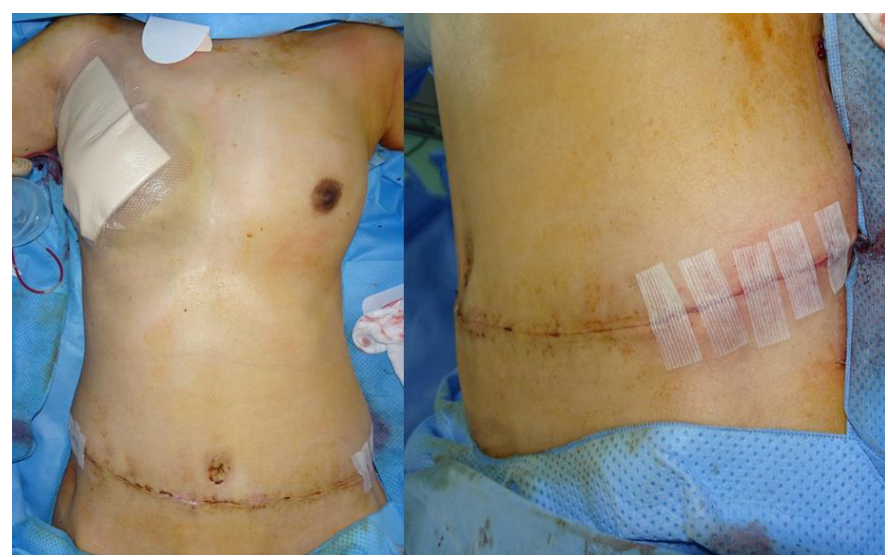

Fig. 4. Immediate postoperative photograph after full-thickness skin graft for mastectomy flap necrosis with secondary procedure for dogear deformity.

Three months after treatment, the graft was stable and the color and texture were satisfactory when compared to the surrounding skin tissue. The dog-ear deformity was also corrected and the patient's satisfaction was good (Fig. 5).

\section{Patient 2}

A 41-year-old woman underwent total mastectomy of the left breast and immediate breast reconstruction using a free DIEP flap with simultaneous reduction mammoplasty of the right breast. Skin necrosis of the left mastectomy flap developed. We performed debridement and an FTSG for skin necrosis of the mastectomy flap. The size of the defect was $6 \times 4 \mathrm{~cm}$, and the donor site was the remaining skin from dog-ear excision of the left flank. The results 


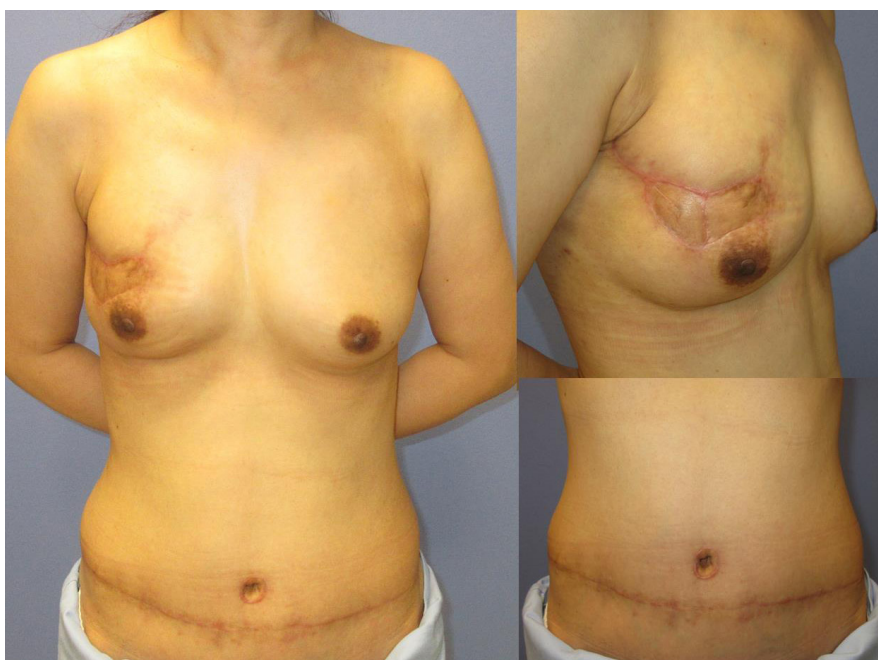

Fig. 5. At the 3 months postoperative day, the graft was stable with harmonious color and texture.

were satisfactory at 9 months after treatment (Fig. 6).

\section{DISCUSSION}

Skin flap necrosis is experienced by $2.5 \%$ to $60 \%$ of patients who undergo mastectomy, making it one of the most common postmastectomy complications. The complication rate varies depending on the surgical technique of the surgeon who performs the mastectomy [2].

Necrosis of mastectomy flaps occurs for various reasons, but the most common cause is a thin remaining skin flap [4]. When performing mastectomy, surgeons have the goal of removing the cancer completely. Therefore, surgeons tend to over-remove soft tissue along with the breast parenchyma.

On the other hand, a dog ear deformity on the flank is the most common aesthetic complaint after autologous breast reconstruction, and it requires a second operation in $28 \%$ of patients [2]. Other studies have reported that more than $10 \%$ of patients require dog-ear correction after breast reconstruction using an abdominal flap $[5,6]$.

Based on these 2 issues, we developed the idea that if mastectomy skin flap necrosis occurs and additional surgical management is needed, we could try to use the excised dog-ear skin flap as an FTSG donor site.

The grafts took well, with no complications. The color and texture were also very harmonious, because the graft and surrounding skin tissue were from the same area (breast and flank).

If a patient experiences post-mastectomy (including skin-sparing mastectomy or NSM) skin flap necrosis and has a dog-ear deformity on both sides of the flank after reconstruction with a DIEP flap, a dog-ear skin flap can be a good alternative donor site for reconstruction.
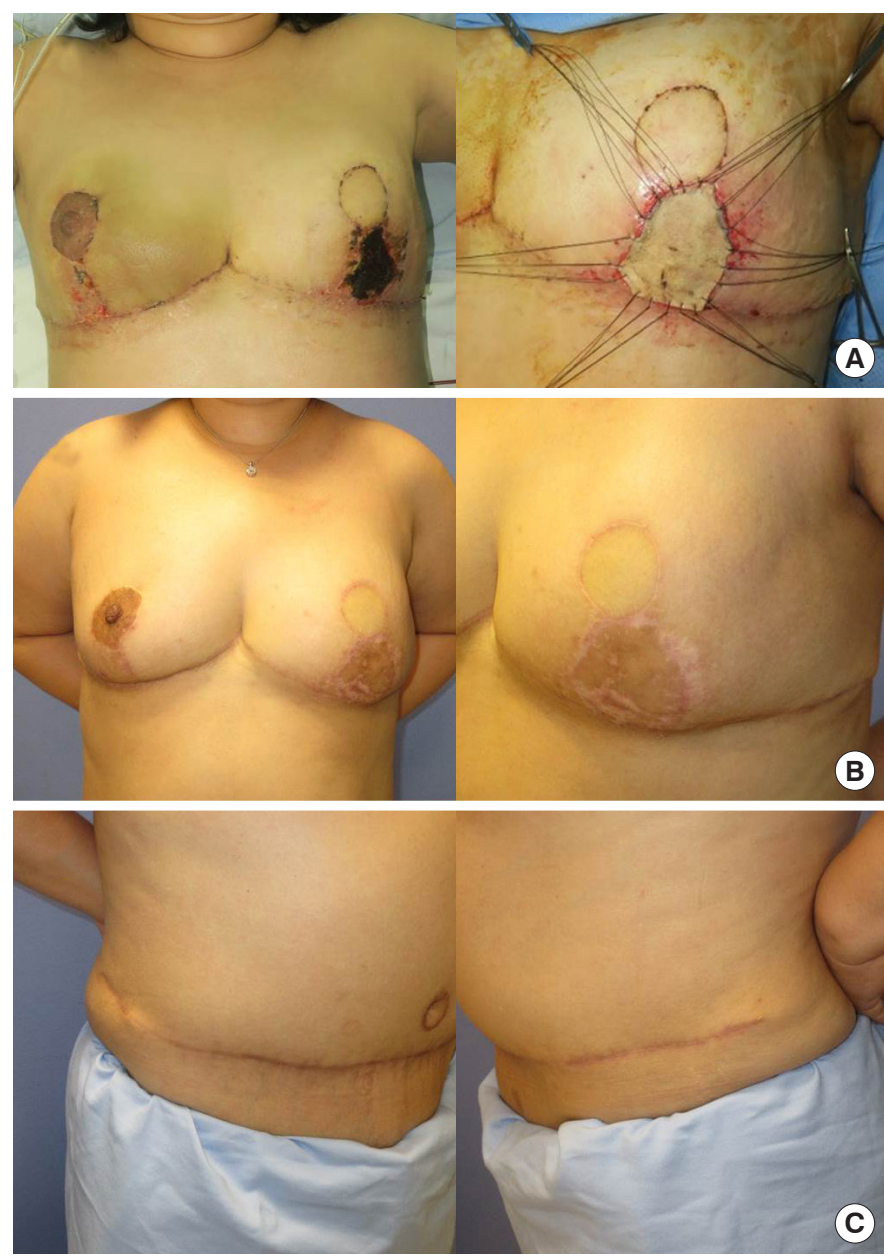

Fig. 6. (A) A patient who underwent total mastectomy of the left breast and immediate breast reconstruction using a free deep inferior epigastric perforator flap with reduction mammoplasty of right breast. The mastectomy flap necrosis was occurred. $(B, C)$ At the 9 months postoperative day.

There are some limitations of the present study. In both cases, the size of the dog-ear was large enough to cover the area of necrosis, but this may not be true in all cases. Second, since the dog-ear flap was obtained from part of the scar tissue, further studies are needed to determine whether it can adversely affect engraftment.

\section{PATIENT CONSENT}

Patients provided written consent for the use of their images.

\section{REFERENCES}

1. Zenn MR. Evaluation of skin viability in nipple sparing mastectomy (NSM). Gland Surg 2018;7:301-7.

2. Komorowski AL, Zanini V, Regolo L, et al. Necrotic complications after nipple- and areola-sparing mastectomy. World J Surg 2006;30:1410-3. 
3. Kim EK, Suh YC, Maldonado AA, et al. Patients' aesthetic concerns after horizontally placed abdominal free flap breast reconstruction. Aesthetic Plast Surg 2015;39:686-93.

4. Robertson SA, Rusby JE, Cutress RI. Determinants of optimal mastectomy skin flap thickness. Br J Surg 2014;101:899-911.

5. Enajat M, Smit JM, Rozen WM, et al. Aesthetic refinements and reop- erative procedures following 370 consecutive DIEP and SIEA flap breast reconstructions: important considerations for patient consent. Aesthetic Plast Surg 2010;34:306-12.

6. Damen TH, Mureau MA, Timman R, et al. The pleasing end result after DIEP flap breast reconstruction: a review of additional operations. J Plast Reconstr Aesthet Surg 2009;62:71-6. 